Please cite as: Guerrero Pico, M., Masanet, M-J., \& Scolari, C.A. (2018). Toward a typology of young produsers: Teenagers' transmedia skills, media production, and narrative and aesthetic appreciation. New Media \& Society. DOI: 10.1177/1461444818796470

Copyright (C) 2018 (Sage Publications). Reprinted with permission of SAGE Publications.

\title{
Towards a Typology of Young Produsers: Teenagers' Transmedia Skills, Media Production, and Narrative and Aesthetic Appreciation
}

\author{
Mar Guerrero-Pico, Maria-Jose Masanet, and Carlos A. Scolari \\ MEDIUM Research Group, Departament de Comunicació \\ Universitat Pompeu Fabra-Barcelona, Spain
}

\begin{abstract}
Based on the qualitative analysis of data from workshops and interviews with teenagers from eight countries, this article aims to determine the degrees of productive, narrative and aesthetic knowledge that teenagers put into practice when they create their media contents. From a theoretical framework that links teens, informal learning environments and participatory cultures, the findings point towards three types of teenage produsers: casual, aspirational, and expert. Each type is representative of different aspects of production in terms of the types of media contents produced; the planning of the production process; the application of narrative and aesthetic values when creating; and the motivations behind the production. The study concludes with an invitation to rethink what participatory culture means in the light of teenagers' production practices.
\end{abstract}

Keywords: adolescents; transmedia skills; informal learning; media production; narrative; produsers; user-generated content; aesthetic 


\section{Introduction}

Ever since Jenkins put the concept of participatory culture (2006), and its offspring transmedia storytelling, on the map there have been countless accounts of how citizens use digital media technologies to empower themselves and acquire the necessary skills to navigate the often complex scenarios of the public sphere. One of these paramount skills revolves around the ability to critically interact, learn and produce with an array of different media platforms from a young age (Gee, 2003; Buckingham, 2007; Jenkins et al. 2016). The transmedia skills that adolescents are acquiring in informal learning settings among their peers away from school and much closer to their everyday interests in the digital world, are at the hub of participatory and collaborative culture (Ito et al., 2013; Scolari, 2018a). This article is based on part of the results of the Transmedia Literacy Research Project (European Union's Horizon 2020 Framework Programme for Research and Innovation Actions). The general aim of the project is to understand what the most active teenagers between 12 and 18 years old are doing with media and where and how they learnt to do that. To answer these questions the project identifies transmedia skills and informal learning strategies developed by teenagers outside school with the objective of introducing these skills and learning strategies into formal education environments. In the context of the present research, transmedia skills are defined as a "series of competences related to digital interactive media production, sharing and consumption. These skills range from problem-solving processes in videogames to content production and sharing in web platforms and social media; the creation, production, sharing and critical consumption of narrative content (fanfiction, fanvids, etc.) by teenagers is also part of this universe" (Scolari, 2018b: 11). Informal learning strategies are defined as "the individual or collective sequence of actions to acquire and accumulate knowledge, skills, attitudes and insights from daily experiences and interactions in different environments" (Scolari, 2018b:11). 
Specifically, this article looks at the project's findings about transmedia skills of production, narrative and aesthetic appreciation to give a more balanced account of how teenagers engage in participatory culture. Based on a qualitative study of data from workshops and interviews undertaken with teenagers from the eight countries of the project, we aim to reveal what degrees of productive, narrative and aesthetic knowledge and reflection comes into play when teenagers are creating their media contents. To put this objective into a context, the first section includes a brief theoretical overview about participatory cultures in relation to transmedia storytelling practices, and it reflects on the critical connections between teenagers, informal learning environments and participatory cultures. The second section reviews the methodology and the tools implemented in the field work and analysis stages of the research. The third section presents a typology of produsers based on the analysis of teenagers' production, narrative and aesthetic skills: casual, aspirational, and expert. Each type is representative of different aspects of production in terms of the types of media contents produced; the planning of the production process; the application of narrative and aesthetic values when creating; and the motivations behind the production.

\section{Transmedia storytelling and participatory cultures}

When we talk about transmedia storytelling (Jenkins, 2006; Scolari, 2009), certain works like Star Wars, Harry Potter, or The Walking Dead always crop up. All these works have something in common: they all tell a story that expands from one medium to another and their fans actively participate in this expansion. Fan communities, with their remixes, parodies, alternate endings, and many other narrative extensions, play a fundamental role in these processes of textual dissemination. Both the cultural and the technological contexts stimulate the production of content by media users. It has never been so easy to produce and disseminate media content. However, in Spreadable Media (2013) Jenkins, Green, and Ford 
warned that fans do more than produce DIY (Do It Yourself) content: the forms of participation are varied and heterogeneous. User participation, in short, cannot be limited to a single view, since it admits, at least, two conceptions: corporate-corporate and participatorypolitical.

According to Jenkins et al. (2006),

Participatory culture shifts the focus of literacy from one of individual expression to community involvement. The new literacies almost all involve social skills developed through collaboration and networking. These skills build on the foundation of traditional literacy, research skills, technical skills, and critical analysis skills taught in the classroom (p. 4)

Jenkins and his team identified different forms of participatory cultures:

- Affiliations: memberships, formal and informal, in online communities centered around various forms of media, such as Facebook, forums, or game clans.

- Expressions: producing new creative forms, such as skinning and modding, vidding, or fan fiction writing.

- Collaborative problem-solving: working together in teams, formal and informal, to complete tasks and develop new knowledge (such as through Wikipedia or spoiling).

- Circulation: shaping the flow of media (such as podcasting or blogging).

Some teenagers are actively involved in participatory cultures. Lange and Ito (2010) argued that the increasing availability of digital media-production tools, combined with sites where young people can post and discuss media works, has created "a new media ecology that supports everyday media creation and sharing for kids engaged in creative production" (p. 244). Digital and online environments are opening new avenues for young people to create and share content, generate new voices and interact with engaged peers and audiences. Collaborative platforms (e.g. Wattpad) and social media (e.g. YouTube) are central territories 
of the new media landscape, a common place for young people to both post and view personal and amateur contents.

\section{Teenagers and participatory cultures}

Researchers such as Jenkins et al. (2006) and Gee (2004) argued that new participatory cultures represent ideal learning environments because they offer powerful opportunities for acquiring new skills. Why do teenagers learn more, participate more actively, and engage more deeply with popular culture than they do with the content of their textbooks? They are sustained by common endeavors that bridge differences in age, class, race, gender, and educational level. People can participate in various ways according to their skills and interests because they depend on peer-to-peer teaching with each participant constantly motivated to acquire new knowledge or refine their existing skills. Finally, participatory cultures allow each participant to feel like an expert while tapping the expertise of others (Jenkins et al, 2006: 9).

According to Jenkins et al. (2006) many new media skills like playing or navigating are being acquired by young people through their participation in informal learning communities. One of the objectives of the present research was to expand the map of transmedia skills that teenagers are developing outside the formal learning system. The concept of 'transmedia skill' developed in the context of the present research includes many more competences than those related to 'transmedia navigation' - that is, the ability to follow the flow of stories and information across multiple modalities - identified by Jenkins et al. (2006:4).

Although some teachers and afterschool programs are incorporating some of these skills into their teaching and activities, in general the integration of these social skills and cultural competencies "remains haphazard at best. Media education is taking place for some 
youth across a variety of contexts, but it is not a central part of the educational experience of all students" (Jenkins et al., 2006: 56-57).

It is important to remember that not all teenagers are 'digital natives', that is, experts in digital technology and content creation. Any research about young people's media practices and skills should avoid the temptation of considering all young people 'digital natives'. The mythology of the 'digital native' - introduced by Prensky (2001) - has been progressively criticized by many other researchers (Helsper and Eynon, 2010; boyd, 2014).

Another essential concept for the present research is 'prosumer' (producer + consumer) or 'produser' (producer + user). The concept of 'produser' (Bruns, 2008) evolved from 'prosumer', a term coined by Toffler (1980) to describe the shift from a passive consumer society to one based on citizens that both consume and created their contents. Researchers like Bird (2011) have made deep reflections on these concepts: Is the mediacreating, Internet-savvy produser indeed the new norm for media consumption? According to Bird, "it is very clear that the majority of people, whether by choice or access to time and resources, are not produsers". At the same time, "the celebration of the Internet-connected fan may blind us to other forms of mediated practices that are equally interesting and relevant" (Bird, 2011: 505). This critique against Jenkins' notion of fandom as a general staple of participatory and convergence culture was also made by Couldry (2011) when he demanded "sociologically grounded reasons for privileging fans as cultural actors in the dynamics of wider convergence practice” (p. 491). Even recent fan scholarship (Linden and Linden, 2017) has questioned views of fandom that are centered solely on its active and participatory facet while neglecting other more passive and individual ways of living it, which further discourages automatic identifications of fandom with participatory culture.

As it can be seen, the crossroad between teenagers, informal learning environments and participatory culture opens a broad spectrum of questions for the researcher: How do 
young people get started on practices such as video production or editing? How do they learn the basics of audiovisual language? What role do online communities play in this informal learning process? This article focuses on a limited set of questions regarding the level of teenagers' narrative and productive practices.

\section{Method}

This study is centered on a section of the overall data of the project and aims to answer the research question: When teenagers are producing their own media contents, what degree of productive, narrative and aesthetic knowledge and reflection comes into play? Based on the pivotal role of production in participatory culture, we focus on the production practices of teenagers that we observed to be most common: Writing, audiovisual and photography production, graphic design and drawing. Special attention is paid to their production processes and to the consideration given to aesthetic and narrative aspects throughout the process. Based on this, we have included a series of secondary questions:

- What are teenagers creating?

- What steps and planning (if any) are applied during the production process?

- Are aesthetic aspects considered in their creations?

- Are narrative aspects considered in their creations?

- Why do they care about the aesthetic and narrative aspects?

To do this, the project followed an ethnographic approach based on the precepts of short-term ethnography (Pink and Morgan, 2013). The ethnographic approach has been proven to be a reliable and well-established methodology for studies in education (for example, Wolcott, 1997; Street, 2014), youth and digital and new media (for example, Horst, Herr-Stephenson, and Robinson, 2010). Short-term ethnography gives us the opportunity to carry out an 
ethnographic approach within a shorter time period than that of traditional ethnography. This means that activities can be carried out in weeks or a few months. As in many other ethnographic works with kids and teenagers, a series of research constraints and requirements, such as the difficulties involved in working with different educational contexts and environments, prevented us from using conventional long-term ethnography, so that the team moved towards short-term ethnography. This methodology is suitable for creating contexts in which researchers can go deeper into research questions in a short and intense period of time. To fulfil the objectives, the project involved a multidisciplinary team who combined different research methods and carried out applied interventions to involve participants in meaningful research contexts (Pink and Morgan, 2013). The research followed five steps:

a) Contact with schools and consent management;

b) An initial questionnaire about teenagers' socio-cultural backgrounds and their media access, habits, uses and perceptions;

c) Creative participatory workshops to immerse the researcher and explore the media practices and universes of the adolescents. These workshops were organized around participatory culture, videogames and social media. During the workshops the research team identified the most active adolescents in the media context for later interviews (d).

d) In-depth interviews and media diaries to deepen discourses about the teenagers' media practices ${ }^{1}$.

e) Online observation of the teenagers' favorite websites, media celebrities, and online communities.

Eight countries participated in this research project (Portugal, Spain, Italy, United Kingdom, Finland, Australia, Uruguay and Colombia) and a total of 1,633 questionnaires, 58 workshops, 311 in-depth interviews and 90 media diaries were completed, and 8 online 
communities were observed. This article focuses on the results from the eight countries and looks exclusively at the data derived from the workshops and interviews, where we worked with teenagers mainly from 12 to 18 years old, although there were some 19-year-olds.

The field work was carried out during the year 2016 and beginning of 2017. Between two and four schools were involved in the project in each country depending on the different educational situations of each country. The following criteria of the schools were considered as dichotomies: private-public, central-periphery, urban-rural, avant-garde or innovative versus more conventional educational model, cultural and ethnic diversity or homogeneity in pupils' demographic composition, and school's policies regarding the implementation of ICT, and the presence or absence of digital audiovisual culture courses, code training programs, ICT infrastructures, etc. when applicable (boyd, 2014). Each country selected the criteria that were more relevant in their particular context, but in general, two or three criteria were related.

NVivo 11 Pro for teams, a computer assisted qualitative data analysis software, was used for the qualitative analysis of data. This software facilitated the development of descriptive and analytical hierarchies through its system of nodes, which permitted us to build thematic categories in response to the elements comprising the research questions.

\section{Analysis}

The data analysis referred to teenagers' media production and how they take into account narrative and aesthetic criteria when they are creating. The results depict a multifaceted scenario that holds in check over enthusiastic views of adolescents' transmedia skills or participatory ventures arising from the 'digital native' mythology. Granted, teenagers are early adopters in that they are more generationally conditioned to interact with digital media and the increasingly lower barriers in access pave the way for this ${ }^{2}$; however, as the project's 
broader body of research demonstrates (Davies and Eynon, 2018; Pereira et al., 2018: Scolari, 2018a), not all young people develop skills at the same pace, navigate through media platforms in the same way, have the same motivations, or apply the same strategies when they learn skills or share content. Based on a subsample of 216 identified teenage produsers - of which 167 produce videos, 117 take photos, 38 draw and design and 38 write stories - we can observe how this figure decreases significantly to 87 teenagers when it comes to skills like appreciating the narrative and aesthetic values of other people's productions. It shrinks even further in relation to planning (76 adolescents) and, especially, to applying narrative and aesthetic values to their own productions (37 teenagers). In other words, the complexity of the production processes carried out follows a declining trend, showing that a seemingly small minority would be able to add narrative and aesthetic values to their own content. Therefore, for the purpose of this article, it is pertinent to consider what the rest of the participating teenagers that fall outside this minority are doing. The data analysis results revealed three produser types: casual, aspirational and expert produsers (Table 1). It should be stressed that these types do not constitute isolated categories so that the expert produser may also carry out practices and processes that are also performed by casual and aspirational produsers. In this sense, the typology resembles the functioning of a matrioshka doll where the larger unit (expert) can include the practices and processes of the smaller ones within it (aspirational and casual). However, the methods applied did not make it possible to observe shifts from casual and aspirational to expert produsage in real time but rather they facilitated identifying those teenagers who already stand out as expert produsers.

\begin{tabular}{|l|l|l|l|}
\cline { 2 - 4 } \multicolumn{1}{c|}{} & Casual & Aspirational & Expert \\
\hline Type of production & Photos and videos & $\begin{array}{l}\text { Writing, photos, } \\
\text { videos, graphic design }\end{array}$ & $\begin{array}{l}\text { Writing, photos, } \\
\text { videos, graphic design }\end{array}$ \\
\hline
\end{tabular}




\begin{tabular}{|l|l|l|l|}
\hline & and drawing & and drawing \\
\hline Planning & $\begin{array}{l}\text { Spontaneous and } \\
\text { simple }\end{array}$ & Moderately planned & Highly planned \\
\hline $\begin{array}{l}\text { Consideration and use } \\
\text { of narrative and } \\
\text { aesthetic values }\end{array}$ & $\begin{array}{l}\text { Not important. Basic } \\
\text { techniques and } \\
\text { concepts are applied. }\end{array}$ & $\begin{array}{l}\text { Very important. } \\
\text { Eagerness to learn and } \\
\text { apply new techniques } \\
\text { and concepts. }\end{array}$ & $\begin{array}{l}\text { Very important. Media } \\
\text { encyclopedic } \\
\text { various techniques and } \\
\text { concepts. }\end{array}$ \\
\hline Motivation & $\begin{array}{l}\text { Entertainment and } \\
\text { relationship with peers }\end{array}$ & $\begin{array}{l}\text { Skill improvement and } \\
\text { peer recognition }\end{array}$ & $\begin{array}{l}\text { Skill improvement and } \\
\text { originality }\end{array}$ \\
\hline
\end{tabular}

Table 1. Produser types. Authors' elaboration.

\section{The casual produser}

The casual produser is a teenager who can produce massively but their production is mainly focused on photos and videos that are mostly shared on social media that could be defined as 'closed', like WhatsApp or Snapchat. In these social media, adolescents share their productions with their close circle of friends, their peers and family, and therefore, these spaces imply a more affiliative participation (Jenkins et al., 2013), or control over their audience (Fortier and Burkell, 2016). However, we can also find cases in which the casual produsers share their creations in 'open' social media like YouTube or Facebook. Their network of followers is usually small and their interventions are more occasional. For example, in the case of Elias, a 13-years-old boy from Uruguay: "once with some friends we made a band and we uploaded a music video, but I think we've already deleted it”.

In fact, the adolescents themselves highlight the production differences related to 'open' and 'closed' social media. They consider that in open social media the photos have to be more elaborated and meticulous and in closed social media you can upload pictures of your 
day to day life. Nora, a 17-years-old girl from Spain, explains: "Snapchat is more... your life... I don't know, maybe here [on Instagram] what you do is upload your pretty pictures, you know, with editor and everything... and on Snapchat it's more... if you want to upload the photo, you upload it... Maybe on Instagram you plan the photo you are going to upload a little bit more...".

And this would be one of the main characteristics of the casual produser: the spontaneous and unplanned production that aims to represent moments of the user's daily life. In these products we find both representations of the environment and of the self, and this second tendency is mainly done with selfies. A group of girls explained this in a workshop organized in Spain. They claim to spend a lot of time on the weekend taking photos on the street and sharing them on Snapchat later. The image becomes, in this way, a quick and simple resource to explain the moments or actions they are doing and experiencing. Another practice that is even more simple is when adolescents send photos of school notes or tasks to their classmates, like Michael, a 14 year-old boy from Colombia explains: "The bell rang and I wasn't done yet. So, I took a photo and sent it to a mate so he could do the homework". Instead of explaining and describing the activity, they opt for the visual representation, which has become the most comfortable and quickest option for them. In these specific cases the product does not undergo any previous planning or later manipulation. It is the most basic production found, in which the image serves as a resource for providing information but content is the important element, not its formal representation.

In the images centered on the personal self or experiences, the planning is also very simple because the photo is taken following very basic criteria, such as including all the subjects in the image or that they all look good. But in these cases, the image is normally manipulated later through the application of filters. However, this is a very generalized and mainly automatic action. Once the picture has been taken, the adolescent usually applies a 
filter available in the options of the social media or the phone camera but they don't look for other complementary software that could be more complete but also more complex to use. Gian, an 18-year-old boy from Italy, expresses it like this: "I only use the phone programs because Photoshop and others are complicated". By applying filters, it is clear that casual produsers are able to appreciate the aesthetic change in the image; however, the main objective, again, is not the aesthetics.

Therefore, as explained above, there is no structured planning of either the preproduction or post-production and the procedure is mainly spontaneous and, in many cases, mechanical. Likewise, their use of the editing tools is instrumental. These tools are incorporated in the social media or phone option but the casual produsers do not look for new options to make a specific aesthetic representation; the tools they have within their easy reach are sufficient for their objectives. Cláudia, a 15-year-old girl from Portugal, explains her process for producing photos and videos: "When I visit new places I usually take pictures of the people I'm with, the places I visit... and I turn them into a video later". When the researcher asked her how she creates these productions, Cláudia admits she doesn't spend a lot of time on them and that often she doesn't make any later modifications. Although she does edit some of her creations, she doesn't even remember the names of the programs she uses: "I edit some photos on my mobile phone, but I don't know specifically the program... they are programs for photos."

The produser's motivations play an important role in this context. Casual produsers mainly make their production motivated by entertainment and strengthening bonds with local peers. In other words, their production practices revolve around what Ito et al. (2010) describe as "hanging out", as a way of extending existing friendships. As commented above, the images and videos are shared mainly with their closest friends, and not with people they don't know. Arto, a 14 year-old male from Finland represents these procedures and motivations: 
“I’ve done some video editing sometimes [...] I've done some gaming videos and remixes, but I've never uploaded them. I've recorded my playing using Bandicam from for example Crossfire and League of Legends. I've used the videos to show some things for my friends through Whatsapp."

Finally, it should be noted that these practices are universal to all types of produsers because most adolescents perform them daily. In this sense, both the aspirational and expert produsers are first casual producers. What differentiates the casual from the aspirational and expert produsers is that their production does not reach higher levels of sophistication and does not address complex aesthetic or narrative aspects. Aspirational and expert produsers use other extra skills in addition to those of the casual produser. Their skills, as explained in the following sections, are developed due to other motivations in addition to "hanging out". And, in the case of the expert produsers, their skills may also be fostered by specific family, cultural or school backgrounds, chiefly related to parents' higher education and a range of cultural interests, or centers' investments in media literacy, whereas casual produsers pose a more diverse scenario in this regard. A likely explanation for this could be attributed to the basic socializing aim behind casual produsage that is shared by most teenagers regardless of their background. Aspirational produsers operate in a similarly diverse context but, again, they are set apart by their motivations.

\section{The aspirational produser}

A significantly number of adolescents showed production skills that would place them in the category of aspirational produsers. These are teenagers who also produce for social media that could be defined as 'open', such as Instagram or YouTube, ideal for encouraging flourishing expressive participation (Jenkins et al., 2013) and focused not so much on everyday relationships but on the products that are shared. These are social media in which adolescents 
can share their productions publicly and, through them, also build their digital identity openly together with a community of followers that surpasses their friends and family. This, of course, entails risks, since the identity is constructed and exposed to external judgment and this can raise a barrier in the production, as we will see later.

It can be observed that aspirational produsers follow a more complex production process than in the previous case. They are mainly produsers of photos and videos but, in some cases, also of writing, graphic design and drawing. This makes them produsers that are close to the ideal of transmedia producer, because they are capable of producing different types of products, and therefore, adapting to the different languages, codes and software that are necessary for the production. As Ito et al. (2010) put it, they "mess around" and explore different forms of media expression. In this way, for example, there are teenagers who produce videos for their YouTube channel but before sharing them they design and create thumbnails and graphic effects that they incorporate into the videos afterwards in the postproduction process. Nestor, a 13-year-old boy from Colombia, includes an introduction to his videos: "I record with a skin called moise, I edit the video, I put music onto it, I take off the original audio and put the music and I say I'm creating an intro and an outro for the channel and I go to YouTube and upload it." This would also be the case of a group of girls who, in a workshop held in Italy, developed a story through Wattpad and presented it through a sequence of slides created with Flipagram. In this way, they not only showed their narrative skills and their adaptation to different languages and tools, but also certain marketing skills.

Planning can be observed in their processes both when they make the product and when they edit it. These are teenagers who look for scenarios and can plan the script of a novel or video as well as the shot of a photo or their situation in the image. As Timo, a 16years-old boy from Finland, evidences: "I do plan a little. When you get more experienced, you start to plan stuff more, like first you pick the music and start to plan according to that." 
And, in some cases, such as the creators of gameplays - adolescents who make videos while they are playing - they also consider the narrative point of view and the storytelling. Thus, for example, situations are observed in which they record a game with different cameras to show the viewpoint of different characters and combine them in the post-production process. To do this, they use different software that can provide more complex and sophisticated options, such as Photoshop, to those offered in social media or mobile phones. They do not settle for just applying a filter but seek to correct what they consider aesthetic errors. Lilac, a 17-yearold girl from Australia, explains how she uses Photoshop: "Sometimes I just use the simplest ones, so brightness, red eyes or cropping. Just the simple, basic skills.” And she justifies why she performs this editing process: "Well, when you take photos you always have these common mistakes and then you use these tools to always fix them. It's like when you cut your hand and you use a Band-Aid, you don't suck. It's like that. That's how I see it."

Another key aspect of the aspirational produsers is their search for inspiration. They do not settle for a standard, common representation of their creations. In order to do this, they look to influencers who are aspirational role models, and therefore, figures to follow and imitate. Some teenagers follow a series of YouTubers or Instagrammers and from the observation and analysis of their productions they find a representation model that they try to imitate and reproduce. Susana, a 16 year-old girl from Colombia, explains that she finds inspiration in an influencer to make her own photos because she considers her original and different. Susana admires this influencer and her discourse shows aesthetic appreciation: "The quality of the photo, I think they work with a Canon and I like those photos very, very much. The landscape, the background they use in the image, for example, she uses different backgrounds so that's what I like very much, the light, that it does not damage the photo but that looks beautiful..." 
A curious situation takes place with aspirational produsers. They not only look for reference models but they also aspire to become a model and it is this motivation that leads them to embark on active learning processes for improving and perfecting their productions. Some teenagers have emphasized their desire to produce unique and original content. In a way, they want to 'set a trend' and become influencers themselves. More than a few teenagers claim to want to get many followers on social media and they think they need to create original products to do this. Therefore, they seek this difference and originality with the objective of making themselves known publicly. Roger, a 12-year-old boy from Australia produces videos with the aim of setting trends: "like be the first one to do this new clip before everyone else copies you, and you make it funny and that." According to the adolescents themselves, to achieve this objective they also need to improve their aesthetic and narrative skills. That is why they also try new production strategies to create different products. But this process is not always successful. In fact, in the project there were several cases of adolescents who, pursuing these objectives, had ended up frustrating themselves and abandoning their activity when they had not achieved the desired aesthetic and narrative results. Their ambition to show themselves publicly and set themselves up as a reference ended up causing the opposite effect, that they stopped producing or sharing their contents.

In the aspirational group we have also observed adolescents who have abandoned their activity or have stopped sharing their products openly for fear of external judgement, as discussed above. Kelly, a 14-year-old girl from the United Kingdom, explains that she created a video and shared it but she is happy that no one knows it is hers: "I've only got one video... I don't really know. It's funny but kind of stupid, but I'm just glad I'm not in it so people don't know it's me." The surprising thing about this case is that Kelly gives very little value to her video; however, her narrative and instrumental knowledge can be appreciated when she explains the procedure she followed. Kelly explains that she made paintings and afterwards 
she animated them with a specific software to create an animated video. It is a complex and time costly procedure: "It takes forever and then there are a lot of things you have to do to it, and then if you forget a step you have to undo it back to that step."

Being very demanding about their products, they consider that they do not have enough quality to be shared and show their concern about external critics. In these cases, some aesthetic and narrative notions can be seen, since their reflections on the quality of their products move in this line. But there are not many instrumental barriers. Except in specific cases, managing software is not usually a problem for aspirational produsers. They have skills with different editing apps and software that tend to be more specialized than those used by casual produsers and they show an interest in continuing to learn about these programs.

With this, it should be noted that there are two factors that can stop the productive and learning activity of aspirational produsers: the frustration of not achieving the goal of becoming a reference model, and the fear of external judgment that comes from the low assessment given to their creations. These processes show that they reflect on their own learning process while "messing around" with media production, and that both their online and offline social environments could hinder achieving their goals if the feedback is negative.

Perhaps as a result, aspirational produsers generally choose to learn on their own, although still benefiting from the openly networked properties of a broader connected learning experience (Ito et al., 2013) that materialize in accessible digital platforms and tools. In light this, it is worth considering what kinds of informal learning strategies are being applied by aspirational produsers. In the context of this research project, Scolari (2018a) identifies six strategies (learning by doing, problem solving, imitation, playing, evaluating, and teaching) that are related to four variables: subject, time, space, and relationships. To help explain the particular case of aspirational produsers, the focus should be placed on relationships. Here, a broad spectrum of situations is observed; from lineal processes of 
knowledge transmission (e.g. a YouTube tutorial) to collective processes of knowledge construction (e.g. forums or pre-game team organization). The particular production practices and social reservations displayed by aspirational produsers seem to favor lineal processes of knowledge transmission instead of embracing a collective and non-lineal approach.

\section{The expert produser}

Finally, we distinguish an expert produser whose occurrence is much more minor and exceptional in comparison to casual and aspirational produsers. Teenagers that fall into this category openly share their productions on social media as seen in the case of aspirational produsers, adhering to the same model of expressive participation (Jenkins et al., 2013). However, experts start from a more experienced position in relation to the use of creation tools. Essentially, experts produsers "geek out" (Ito and el., 2010) and push the limits of their abilities, which leaves room for the cultivation of an advanced set of narrative and aesthetic skills. These competences are very present in their creative processes and in their comments on it, as explained below.

Like aspirational produsers, experts inhabit the same transmedia area when it comes to producing content by combining different languages and codes to achieve the desired representation for the content they have set out to narrate. Yet, here the central role of other media during the process is not just relegated to post-production, or to creating paratexts that surround the primary text, such as the custom thumbnail of a YouTube video. Expert produsers can tell stories with and through different media. Tim, a 13-year-old boy from Australia, incarnates these practices in his account of a YouTube clip he made with his friend Aston that recreates a flooding hallway scene from Titanic. To do this, they built a miniature cardboard corridor and filmed as the water invaded the little scenario. 
The fact that Tim chose to create the setting himself implies a more ambitious approach to content creation than that observed in the other types of produsers. Not only can he film and edit footage but he creates the scenarios for the film's action, which entails being skillful with the use of audiovisual media devices and having active artistic abilities and aesthetic appreciation. His creative partnership with Aston also ties back to accounts of "geeking out" involving social and collective learning processes (Ito et al., 2010). Asked about how they set up and filmed the scene, Tim says: "We set to work with this box, and there was like a t-intersection there. So, with ours there was like a box we chopped, took out half of it and then there was like an extra little wall here and then we had another hallway that we connected to it. So, it was like the t-intersection of a hallway. And the other side was open and there was like the T, a really small one. And there was one really open side where we could pour the water with a bucket into, and we put a camera on this little Lego truck that Aston would pull back through the hallway and yeah, then we added the lighting effects and things."

Teenagers at this level of produsage are full-blown planners. Tim's experience with the Titanic video serves again as an example. Without mentioning the word storyboard, during the interview he pointed at a careful preparation of the hallway scene that involved sketching the scenario on paper and then explained that "the bucket of water was going to go in there, and then this hose is going to kind of run along slowly." According to Tim, the reason behind his choice was related to time control and the impossibility of seeing what is happening when the scene is being filmed. An acute awareness of the specific production requirements like this seems to be generalized among expert produsers, whose attention to detail can sometimes be referred to as perfectionism by some of them.

In addition, experts have broader encyclopedic skills (Eco, 1979) when it comes to appreciating other people's work according to narrative and aesthetic values. In recreating the 
famous blood lift scene from Stanley Kubrick's The Shining for another of his clips, Tim muses: "The meaning behind it is very, very disputed. It was this kind of surreal, you know, easy to see blood that looks kind of like chocolate, you want to eat it. But we used this as the basis for most of our reference because it's slow and it's easy to see what's going on with the liquid and the furniture and it's really light, and it also shows a top down view as well which is really, really useful." Beyond the fact that this teenager handles cultural references not usually associated with 13-year-olds (Tim admits that he learnt "a lot" about cinema history while making the clip) there is a remarkable level of accuracy in his discourse, which deconstructs the evocative elements of the scene from his own perspective. In this sense, expert produsers recognize the varying implicit meanings and intentions of what is represented in media contents and how audiences react to it. These types of considerations translate into a higher attention to these aspects when they create as well as to other aspects pertaining to genre or narrative pacing. This could be observed in one of the workshops in Spain where a group of girls made a trailer for a horror movie. Both in the production process and in the editing process it was observed that one of the girls, 16-years-old Eva, had sophisticated aesthetic and narrative skills. The composition of the shots and the subsequent editing process evidenced her knowledge of the 'script', understanding it from Eco's perspective (1979), which refers to the idea of an encyclopedia that is full of scripts or frames of reference. The girl composed fluently with closed and cold shots that evoked the feeling of danger and fear. Likewise, she accompanied the images with a disturbing soundtrack that accelerated to the rhythm of the images, creating a sensation of suspense and mystery.

Furthermore, as with aspirational produsers, a quest for uniqueness also plays an important role as motivator within this group of produsers. Experts are very self-demanding, perhaps because they are currently addressing larger audiences, or intend to do so in the near future. Sometimes this entails embracing a potential status as influencers for their followers, a 
kind of recognition that pushes them out of their comfort zones to try and learn new things. They put into practice the same process for skill acquisition observed in the other produsers, mainly based on learning by doing and imitation strategies.

Simultaneously, some experts are starting to flirt with the possibilities of obtaining economic benefits from their productions, which also acts as a motivating force in some cases: "I hit 1000 subscribers and it kind of happened quite quickly, and then I set up an account which Googles [sic] the monetary thing, and I actually made $£ 80$ off there when I was uploading my videos" (Jamie, 14 years old, male, UK). Nonetheless, it is necessary to add some nuances to the pull that open social media platforms may exert over expert produsers. As seen throughout this research, and to varying degrees depending on the country and social context, there are cases of adolescents who have advanced narrative and aesthetics skills but are not keen on sharing productions or expressions of themselves in public. It can be concluded that fear of other people's judgment does deter some adolescents from exploring different opportunities of connecting and participating meaningfully through the development and diffusion of their skills. However, it should be highlighted that experts generally start from a more privileged socio-cultural position than casual and aspirational produsers from which they can overcome those fears as well as enhance their narrative and aesthetic skills. Being surrounded by nurturing familial and educational contexts may then be crucial to promoting adolescents' confidence in their creative pursuits. In expert produsage, it is frequent to find accounts of households with at least one culturally-interested parent who either shares their hobbies with their children or participates in their media endeavors. For instance, Aston's father makes little furniture and he made a miniature table so that Aston and Tim could include it in their recreation of the Titanic scene. Sometimes the support comes from the staff of a semi-private school which has incorporated media literacy in their 
curriculum since kindergarten, as Eva mentions when she enthusiastically reminisced about her early lessons on a subject related to didactics of the image.

\section{Discussion}

As suggested at the beginning of this article, teenagers are doing things with media and learning through them. Besides consuming, the most active teens are using media to produce content. Therefore, it can be assumed that teenagers are contributing to the larger contexts of participatory culture, whose reason for being is providing consumers and citizens with the ability to (re)create, (re)appropriate and (re)distribute their own content supported by the development of digital media. At the same time, such production permits citizens to shape social connections that are fundamental to the development of democratic societies. Given the capital role of consumers and citizens' media production in the spread of participatory culture, and its ramifications for teenagers' transmedia literacy, it is appropriate to start re-examining what participatory culture means in a context where media production seems to be so accessible, or where participation itself has turned into "a general condition of everyday life... both environmental and normative" (Barney et al., 2016: vii). But, are all forms of participation equally meaningful as Linden and Linden (2017: 57) put into question? By introducing a typology of young produsers in relation to the narrative and aesthetic knowledge applied when they create their own content, we sought to shed some light on this question.

Casual, aspirational and expert produsers reveal different paths in participatory culture that stress the necessity to keep fostering and cultivating other relevant skills for media literacy in addition and simultaneously to media production. Some of these abilities revolve around narrative and aesthetic appreciation, but they can also include abilities related to observing and reflecting on the ideology and values promoted by corporate media products 
and their own contents. The recurrence of these abilities is uncommon. It is important to note that the project findings come from a small sample of active adolescents, so the presence of these complementary yet essential skills was expected to be singular and limited. In any case these outcomes cannot be extrapolated to all teenagers but rather should be interpreted as a trend among some of them. Moreover, expert produsage is a scattered phenomenon that varies through countries and socio-economic and educational backgrounds, which confirms results found in other studies (Eynon and Geniets, 2016; Byrne et al., 2016). As observed, family contexts can be key in amplifying certain processes and practices associated with narrative and aesthetic appreciation, which loosely points towards Lareau's (2003) concept of "concerted cultivation", that is, parents actively stimulating and validating their children's talents. A similar assessment can be applied to school settings; the more educational centers boost these skills in the school curriculum, while creating inclusive and inviting learning spaces for adolescents and parents, the more gaps will be closed in potentiating the acquisition of these skills.

The fact that there are expert produsers with additional abilities to those of their peers does not prevent those same produsers from sliding towards aspirational, or even casual positions in other scenes of their media usage, or in their daily communications with peers. This typology is not mutually exclusive and it intends to reflect the richness of environments and learning curves that teenagers may navigate when they interact and produce with media. It should not be understood as fixed 'levels' of a 'participation pyramid' where the expert produsers are always situated at the top of the construction. On the contrary, we prefer to think of this ideal type as part of a complex and evolving network of engagement and participatory practices. Barnes (2014), whose work is heavily influenced by fan studies, identified three modalities of audience participation: active contributors, engaged listeners, and distributors. She introduces the concept of 'ecology of participation', a place where "fan- 
like behaviours, in particular emotional engagement and negotiation of identity, play a significant role" (p. 555). Therefore, our three types of produser emerge and operate within this framework.

In a sense, aspirational produsers' advances and struggles can be considered an accurate embodiment of the learning processes that occur in informal settings. As Ito et al. (2013) state, personal interests and peer support drive teenagers' learning. Indeed, the motivation of aspirational, but also expert produsers to upskill themselves is chiefly linked to wanting to improve their productions and to gaining recognition among their peers. However, recent research (Pereira et al., 2018) points towards different subtleties to this approach. These catalysts for learning can turn into limiting forces for skill acquisition if teenagers are not informed about the opportunities provided by abilities and critical toolkits dwelling in other activities outside their interests, or precisely, if that desire for recognition runs parallel with fear of other people's opinions so that it hinders their creative enterprises. In this sense, further research should be carried out to assess and provide advice on how to act upon these constraints to the development of teenagers' identities and transmedia skills on which the evolution and survival of a more purposeful and significant participatory culture depend.

\section{Funding}

This work has received funding from the European Union's Horizon 2020 Framework Programme for Research and Innovation Actions under Grant Agreement Number 645238.

\section{Notes}

1. Only a few adolescents completed the media diaries because they had to do it at home and in their free time.

2. The 1,633 adolescents that took part in the questionnaire have regular access to the Internet and to smartphones as their primary digital device. 


\section{References}

Barnes R (2014) The “ecology of participation”. Digital Journalism, 2(4). DOI:

$10.1080 / 21670811.2013 .859863$

Barney D, Coleman G, Ross C, Sterne J, and Tembeck, T (2016) The participatory condition: An introduction. In: Barney D, Coleman G, Ross C, Sterne J and Tembeck T (eds) The participatory condition in the digital age. Minneapolis, MN: University of Minnesota Press, pp. vii-xxxix.

Bird ES (2011) Are we all produsers now? Cultural Studies 25(4-5): 502-516. DOI:

$10.1080 / 09502386.2011 .600532$

Buckingham D (2007) Media Education: literacy, learning and contemporary culture

(Reprinted. ed.). Cambridge: Polity Press.

boyd d (2014) It's Complicated: the social lives of networked teens. London / New Haven: Yale University Press.

Bruns A (2008) Blogs, Wikipedia, Second Life and Beyond: From Production to Produsage. New York: Peter Lang.

Byrne J, Kardefelt-Winther D, Livingstone S, Stoilova M (2016) Global Kids Online research synthesis, 2015-2016. Report, UNICEF Office of Research-Innocenti and London School of Economics and Political Science. Available at: www.globalkidsonline.net/synthesis (accessed 5 April 2018).

Couldry N (2011) More sociology, more culture, more politics: or, a modest proposal for 'convergence' studies. Cultural studies 25(4-5): 87-501.

Davies HC and Eynon R (2018) Is digital upskilling the next generation our pipeline to prosperity? New Media and Society. DOI: 10.1177/1461444818783102

Eco U (1979) Lector in Fabula. Milan: Bompiani. 
Eynon R and Geniets, A (2016) The digital skills paradox: how do digitally excluded youth develop skills to use the internet? Learning, Media and Technology 41(3). DOI: $10.1080 / 17439884.2014 .1002845$

Fortier A and Burkell J (2016) Display and control in online social spaces: Towards a typology of users. New Media \& Society 20(3): 845-861. DOI $10.1177 / 1461444816675184$

Gee JP (2003) What video games have to teach us about learning and literacy. New York: Palgrave Macmillan.

Gee JP (2004) Situated Language and Learning. A critique of traditional schooling. New York: Routledge.

Helsper E and Eynon R (2010) Digital natives: where is the evidence? British educational research journal 36(3): 503-520. DOI: https://doi.org/10.1080/01411920902989227

Horst HA, Herr-Stephenson B and Robinson L (2010) Media Ecologies. In: Ito M et al. Hanging Out, Messing Around, and Geeking Out: Kids Living and Learning with New Media. Cambridge, MA: MIT, pp. 29-77.

Ito M et al. (2010) Hanging Out, Messing Around, and Geeking Out: Kids Living and Learning with New Media. Cambridge, MA: The MIT Press.

Ito M, Gutierrez K, Livingstone S, Penuel B, Rhodes J, Salen K, Schor J, Sefton-Green J and Watkins SC (2013) Connected Learning: An agenda for Research and Design. Irvine, CA: Digital Media and Learning Research Hub.

Jenkins H (2006) Convergence Culture. Where old and new media collide. New York, NY: New York University Press.

Jenkins H, Clinton K, Purushotma R, Robison A and Weigel M (2006) Confronting the Challenges of Participatory Culture: Media Education for the 21st Century. Chicago, IL: MacArthur Foundation. 
Jenkins H, Green J and Ford S (2013) Spreadable Media: Creating Value and Meaning in a Networked Culture. New York: NYU Press.

Laureau A (2003) Unequal childhoods. Class, race and family life. Berkeley and Los Angeles (CA): University of California Press.

Linden H and Linden S (2017) Fans and fan cultures. Basingstoke and New York, NY: Palgrave Macmillan.

Lange P and Ito M (2010) Creative production. In: Ito M et al. Hanging Out, Messing Around, and Geeking Out: Kids Living and Learning with New Media. Cambridge, MA: The MIT Press, pp. 243-293.

Pereira S, Moura P, Masanet M-J, Taddeo G and Tirocchi S (2018) Media uses and production practices: case study with teens from Portugal, Spain, and Italy. Comunicación y Sociedad, 33: 89-114.

Pink S and Morgan J (2013) Short-term ethnography: intense routes to knowing. Symbolic Interaction 36(3): 351-361.

Prensky M (2001) Digital Natives, Digital Immigrants: Part 1. On the Horizon 9(5): 1-6.

Scolari CA (2009) Transmedia Storytelling. Implicit consumers, narrative worlds and branding in contemporary media production. International Journal of Communication 3: $586-606$.

Scolari CA (Ed) (2018a) Teens, Media, and Collaborative Cultures. Exploiting Teens's Transmedia Skills in the Classroom. Barcelona: H2020 TRANSLITERACY Research Project/Universitat Pompeu Fabra.

Scolari CA (2018b) Transmedia Literacy in the New Media Ecology: White Paper. Barcelona: H2020 TRANSLITERACY Research Project/Universitat Pompeu Fabra. 
Street BV (2014) Social literacies: Critical approaches to literacy in development, ethnography and education. London: Routledge.

Toffler A (1980) The Third Wave: The classic study of tomorrow. New York: Bantam.

Wolcott H (1997) Ethnographic research in education. In: Jaeger R (ed) Complementary methods for research in education. London: Routledge, pp. 327-353. 